Check for updates

Cite this: Mater. Chem. Front., 2019, 3, 1123

Received 16th March 2019,

Accepted 3rd April 2019

DOI: 10.1039/c9qm00158a

rsc.li/frontiers-materials

\section{Heavy atom-free semiconducting polymer with high singlet oxygen quantum yield for prostate cancer synergistic phototherapy $\dagger$}

\author{
Jian Shen, ${ }^{\mathrm{a}}$ Jianjiao Chen, ${ }^{\mathrm{b}}$ Zhen Ke, ${ }^{\mathrm{b}}$ Dengfeng Zou, (D) ${ }^{\mathrm{b}}$ Liguo Sun ${ }^{\star \mathrm{a}}$ and \\ Jianhua Zou (iD *bc
}

\begin{abstract}
Photodynamic and photothermal synergistic therapy are newly developed approaches for cancer treatment. The design and preparation of photosensitizers of high phototoxicity as well as low dark toxicity are of increasing significance in minimizing the side effects and maximizing the phototherapy efficacy of such treatments. In this study, a heavy atom-free copolymer NDNT was designed and synthesized by the Stille coupling reaction. This compound shows a high singlet oxygen quantum yield of $55.2 \%$, guaranteeing an excellent phototherapy efficacy. The nanoparticles (NPs) of NDNT obtained by nanoprecipitation with DSPE-PEG-2000 with an average diameter of $65 \mathrm{~nm}$ exhibit considerably high phototoxicity towards human prostate cancer cells (Du145) because their half inhibitory concentration $\left(\mathrm{IC}_{50}\right)$ is as low as $3.8 \mu \mathrm{g} \mathrm{mL} \mathrm{L}^{-1}$. Simultaneously, the dark toxicity of the NPs is almost negligible, even at a high concentration. Furthermore, an in vivo study with laser irradiation by photodynamic and photothermal synergistic therapy demonstrates that the NPs are capable of inhibiting a Du145 tumor growth, compared with the control and dark group, suggesting the low dark toxicity and high phototoxicity of such NPs. The H\&E stained pictures of the normal tissues show that no obvious damage occurred, indicating the biosafety of the NDNT NPs. These results provide a strategy for designing heavy atom-free copolymers for phototherapy both in vitro and in vivo.
\end{abstract}

\section{Introduction}

At present, malignant tumors have become the second leading cause for human death, and people in growing numbers are suffering from cancer worldwide, following heart disease. ${ }^{1}$ Among the various cancers, prostate cancer is a universal challenge to man. Patients undergoing traditional cancer therapies, including surgery, radiation and chemotherapy, can have a higher possibility to suffer from side effects and a second recurrence of tumor. ${ }^{2-6}$ Although surgery is aimed at completely removing the tumor as much as possible, the prostate is often closely adhered to the surrounding tissues, with the characteristic of invasive growth, and strong recurrence, thus leading to the difficulty in removing the tumor tissue completely. ${ }^{5}$ Traditional drugs usually cause severe toxicity and side effects, and also lead to the condition of multiple

\footnotetext{
${ }^{a}$ Department of Urology, Changshu No. 2 People's Hospital, 215500, Jiangsu, P. R. China. E-mail: 13338729262@163.com

${ }^{b}$ School of Pharmacy, Guilin Medical University, Guilin 541004, Guangxi, P. R. China. E-mail: zoujh93@126.com

'Jiangsu Laboratory of Advanced Materials, Department of Chemistry and Materials Engineering, Changshu Institute of Technology, Changshu, 215500, Jiangsu,

P. R. China

$\dagger$ Electronic supplementary information (ESI) available. See DOI: 10.1039/c9qm00158a
}

drug resistance. Based on these observations, it is urgent to explore and discover effective treatment methods for such a common and serious disease. ${ }^{7-10}$

Phototherapy, including photodynamic therapy and photothermal therapy, is an invasive technique for tumor treatment. ${ }^{11-19}$ Compared with traditional treatment methods, phototherapy has a therapeutic effect on a variety of tumors, does not produce drug resistance, and after long-term follow-up and evaluation. Furthermore, the photosensitizers can target the specific tumor site without causing damage to the surrounding normal tissues. ${ }^{20-25}$

Photosensitizers (PSs) play an important role in the phototherapy process. High phototoxicity as well as low dark toxicity may maximize the efficacy and simultaneously minimize the side effects. The high singlet oxygen quantum yield $\left({ }^{1} \mathrm{O}_{2} \mathrm{QY}\right)$ and photothermal conversion efficiency of PSs may promise an excellent therapy efficacy. ${ }^{26}$ Heavy atoms are often conjugated to the molecule to enhance the ${ }^{1} \mathrm{O}_{2}$ QY via spin orbit crossing (SOC), but they may contribute to the dark toxicity of the PS itself. Heavy atom-free PS may lower the potential of dark toxicity, the design and preparation of which is of tremendous interest. PS with near infrared region (NIR) may have better penetration depth. ${ }^{27-30}$

In this study, a heavy atom-free copolymer was prepared by the Stille coupling reaction for cancer therapy (Scheme 1). 


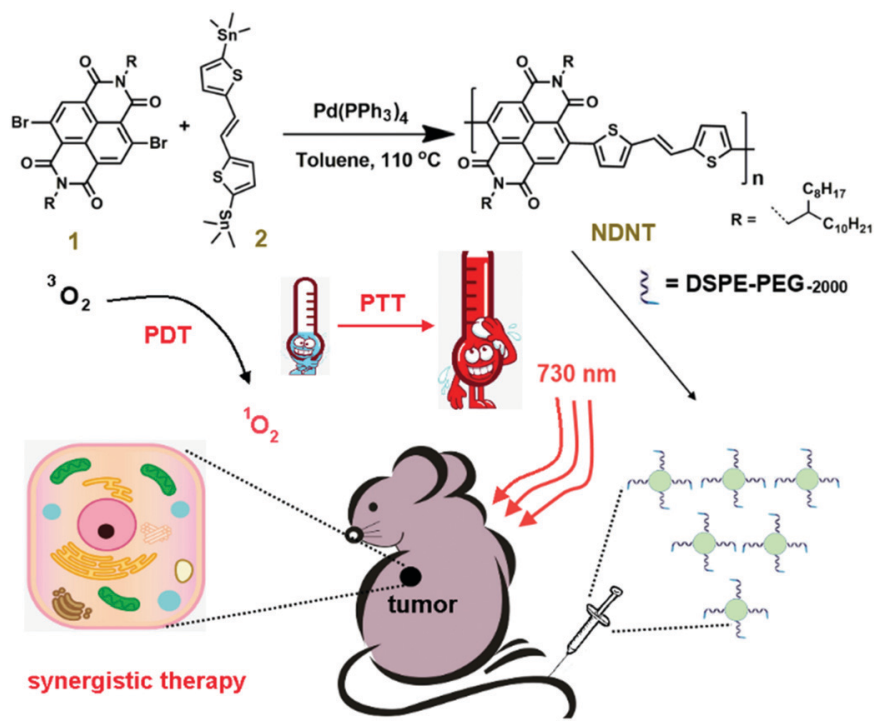

Scheme 1 Synthesis of NDNT and illustration of its NPs for phototherapy.

The as-obtained NDNT with NIR absorbance $(730 \mathrm{~nm})$ has a high ${ }^{1} \mathrm{O}_{2}$ QY of $55.2 \%$, with methylene blue as a standard substance in DCM. Nanoprecipitation was used to prepare the water soluble NPs with average diameter of $65 \mathrm{~nm}$, which were suitable for in vitro and in vivo study. An MTT assay shows that NDNT NPs have an ultralow half inhibitory concentration $\left(\mathrm{IC}_{50}\right)$ of $3.8 \mu \mathrm{g} \mathrm{mL} \mathrm{m}^{-1}$ and a negligible dark toxicity even at high concentrations. An in vivo study demonstrates that NDNT NPs can effectively inhibit the tumor growth, while the normal tissues, including the spleen, liver, kidney, heart and lung, suffer from no damage. Our results suggest that NDNT NPs are a potential candidate for phototherapy.

\section{Experimental}

\section{Materials and apparatus}

Except for NDNT, all the chemicals were commercially purchased from Sigma and were used without further purification. ${ }^{1} \mathrm{H}$ NMR and ${ }^{13} \mathrm{C}$ NMR spectra were recorded on a Bruker DRX $\mathrm{NMR}$ spectrometer in $\mathrm{CDCl}_{3}$ at $298 \mathrm{~K}$ with residual solvent $\left(\mathrm{CDCl}_{3}, \delta=7.26 \mathrm{ppm}\right)$ as the internal standard. UV-vis spectra were recorded on a spectrophotometer (UV-3600 UV-Vis-NIR, Shimadzu, Japan). Fluorescence spectra were recorded on an F-4600 spectrometer (HITACHI, Japan). TEM images of the nanoparticles were recorded on a JEOL JEM-2100 equipment. DLS was measured on a 90 Plus particle size analyzer (Brookhaven Instruments, USA).

\section{Synthesis and characterization of NDNT}

Compound 1 (98.50 mg, $0.1 \mathrm{mmol}$ ) and compound 2 (51.80 mg, $0.1 \mathrm{mmol})$ were dissolved in anhydrous toluene $(5 \mathrm{~mL})$, to which $\mathrm{Pd}\left(\mathrm{PPh}_{3}\right)_{4}(4.65 \mathrm{mg}, 0.004 \mathrm{mmol})$ was added. The solution mixture was stirred at $110{ }^{\circ} \mathrm{C}$ for $16 \mathrm{~h}$ under an argon atmosphere. After cooling to ambient temperature, the reaction mixture was poured into methanol $(200 \mathrm{~mL})$. The isolated crude product was then subjected to Soxhlet extraction with methanol, hexane and acetone. Finally, the product was extracted with chloroform, which was concentrated before being precipitated with methanol again, affording a dark solid. Yield: $158 \mathrm{mg}, 78 \%$. $\delta \mathrm{H}\left(400 \mathrm{MHz}, \mathrm{CDCl}_{3}\right): 8.80-8.50(2 \mathrm{H}, \mathrm{br}), 7.26-7.15(2 \mathrm{H}, \mathrm{br})$, 7.14-6.99 (4 H, br), 4.18-4.10 (4 H, br), 2.12-1.97 (2 H, br), 1.50-1.16 (64 H, br), 0.90-0.80 (12 H, br). $M_{\mathrm{w}} / M_{\mathrm{n}}$ (GPC) $50.8 \mathrm{k} /$ $31.4 \mathrm{k} . T_{\mathrm{d}}(\mathrm{TGA})=438{ }^{\circ} \mathrm{C}$.

\section{Preparation of the NDNT nanoparticles}

The nanoparticles of NDNT were prepared by nanoprecipitation with DSPE-PEG -2000. DSPE-PEG $_{-2000}(5 \mathrm{mg})$ was first dissolved in distilled water using ultrasound. Then, NDNT (5 mg) was dissolved in tetrahydrofuran (THF, $1 \mathrm{~mL}$ ) and $200 \mu \mathrm{L}$ of the NDNT solution was injected into PBS with ultrasound at room temperature. After the mixture was stirred for $10 \mathrm{~min}$, the THF was removed by purging the solution with nitrogen. The product was then frozen and dried for further use.

\section{Cell culture and MTT assay}

At $37^{\circ} \mathrm{C}$, human prostate cancer Du145 cell lines were cultured in a medium made up of Dulbecco's modified Eagle's medium (DMEM, Gibco) with 10\% fetal bovine serum (FBS) under an atmosphere of $5 \% \mathrm{CO}_{2}$. NDNT NPs were first dissolved in distilled water, which were then diluted with DMEM to various concentrations (0-6 $\mu \mathrm{g} \mathrm{mL}^{-1}$ ) and put into a 96-well plate. Then, the plate was irradiated with a laser $\left(730 \mathrm{~nm}, 1 \mathrm{~W} \mathrm{~cm}^{-2}\right)$ for 5 minutes. The relative cell viability was determined using a MTT (3-(4,5-dimethylthiazol-2-yl)-2,5-diphenyltetrazolium bromide) assay. The MTT solution in distilled water $\left(5 \mathrm{mg} \mathrm{mL}^{-1}, 20 \mu \mathrm{L}\right)$ was added to each well followed by incubation for $4 \mathrm{~h}$ under the same conditions at $37{ }^{\circ} \mathrm{C}$. The solution was then discarded, followed by the addition of DMSO $(200 \mu \mathrm{L})$ to each well. At ambient temperature, the absorbance was measured on a Bio-Tek microplate reader. The cell viability of the control group was considered to be $100 \%$. The relative cell viability was then calculated by the following equation: viability $(\%)=$ mean absorbance of the group incubated with NDNT NPs/mean absorbance of the group incubated with DMEM.

\section{In vitro cellular uptake and fluorescence image of cellular ROS}

Du145 cells were incubated with DSPE-PEG ${ }_{-2000}$-coated NDNT NPs $\left(3.8 \mu \mathrm{g} \mathrm{mL} \mathrm{m}^{-1}, 2 \mathrm{~mL}\right)$ in a confocal dish for different time in the dark over $24 \mathrm{~h}$. Then, the solution was discarded and the cells were washed with PBS three times $(1 \mathrm{~mL})$, and then $1 \mathrm{~mL}$ polyoxymethylene was added for $25 \mathrm{~min}$. Subsequently, the polyoxymethylene was discarded and the cells were washed with PBS $(1 \mathrm{~mL})$ for three times. The sample that had been incubated for $24 \mathrm{~h}$ with NDNT NPs was further cultured with 2,7-dichlorodihydrofluorescein diacetate (DCF-DA, $10 \mu \mathrm{mol}$ ) for $5 \mathrm{~min}$. Following this, the dish was washed with PBS $(1 \mathrm{~mL})$ three times. This sample was irradiated with a laser for 3 minutes (730 nm, $1 \mathrm{~W} \mathrm{~cm}^{-2}$ ). The samples that had not been incubated with NDNT NPs for $24 \mathrm{~h}$ were excited at the wavelength of $633 \mathrm{~nm}$ and the resultant fluorescence from 650 to $750 \mathrm{~nm}$ measured. The in vitro ROS generation was excited with a $488 \mathrm{~nm}$ laser and fluorescence from 490 to $600 \mathrm{~nm}$ was measured. 


\section{In vivo tumor treatment histology examination}

The study complies with all institutional, national guidelines and National Institutes of Health. The protocol was approved by the Animal Center of Guilin Medical University (SCXK2007001). 15 nude mice were purchased and then injected with Du145 cells into the armpit as the tumor source. These mice were then randomly divided into 3 groups randomly when the tumor volume reached about $100 \mathrm{~mm}^{3}$. For the control group, the mice were intravenously injected with a saline solution, while the other groups were injected with NDNT NPs $\left(38 \mu \mathrm{g} \mathrm{mL}{ }^{-1}\right.$, $100 \mu \mathrm{L}$ ) in saline solution. After $4 \mathrm{~h}$, the tumors of certain mice were irradiated by a laser $\left(730 \mathrm{~nm}, 1 \mathrm{~W} \mathrm{~cm}^{-2}\right)$ for 8 minutes, while the other group of mice were not irradiated. The experiment was continued for 28 days, and the tumor volume and body weight of the mice were recorded every two days. These nude mice were sacrificed followed by the histology analysis. The main organs (heart, liver, spleen, lung, kidney) and the tumor was isolated and fixed in $4 \%$ formaldehyde solution. After dehydration, they were embedded in paraffin cassettes and stained with hematoxylin and eosin (H\&E), and the images were recorded on a microscope.

\section{Results and discussion}

\section{Synthesis and characterization of NDTT and NPs}

As shown in Fig. 1A, NDNT NPs exhibited broad absorption peaks at 730 and $822 \mathrm{~nm}$, while NDNT in DCM shows absorption with maximum intensity at $720 \mathrm{~nm}$. For the emission spectra, NDNT shows emission with maximum intensity at $732 \mathrm{~nm}$ (Fig. 1B), while emission with a red shift of $36 \mathrm{~nm}$ was found for its nanoparticles. NDNT shows emission with a maximum intensity at $768 \mathrm{~nm}$. The red-shift of $10 \mathrm{~nm}$ is caused by aggregation in water.

Then, the morphology and diameter of the nanoparticles were characterized using transmission electron microscope (TEM) and dynamic light scattering (DLS).
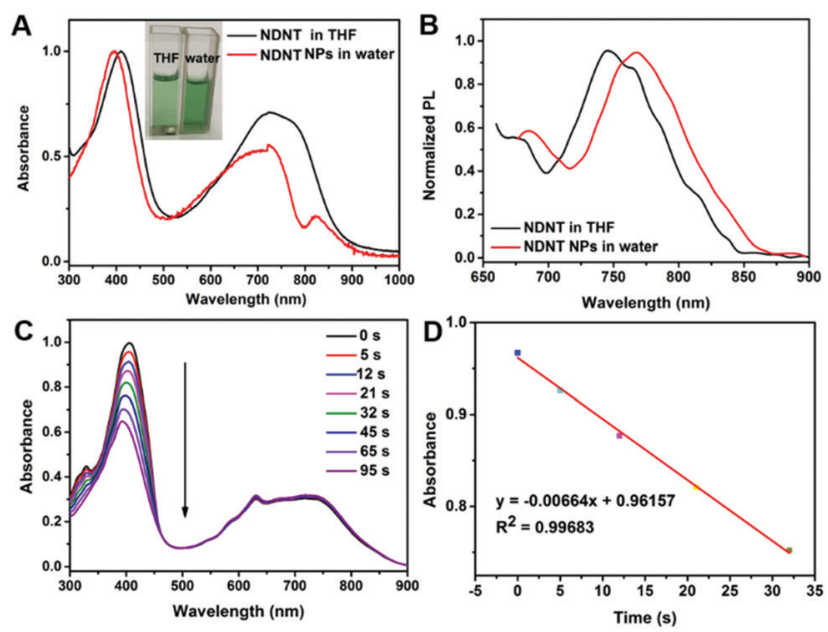

Fig. 1 (A) Normalized absorbance of NDNT in THF and NPs in water; (B) normalized PL of NDNT in THF and NPs in water; (C) degradation of DPBF under the presence of NDNT in DCM with laser irradiation; (D) linear fitting of the degradation of DPBF.
High singlet oxygen quantum yield $\left({ }^{1} \mathrm{O}_{2} \mathrm{QY}\right)$ promises excellent phototoxicity for a photosensitizer. The ${ }^{1} \mathrm{O}_{2}$ QY was determined using 1,3-diphenylisobenzofuran (DPBF) as a probe with methylene blue (MB) as a standard in DCM. As shown in Fig. 1C and D, the absorbance of DPBF degrades at a high speed with laser irradiation, and the ${ }^{1} \mathrm{O}_{2}$ QY calculated is as high as $55.2 \%$. It is worth pointing out that the copolymer is heavy atom-free but possesses a high ${ }^{1} \mathrm{O}_{2}$ QY, which may cause a reduction in the potential dark toxicity.

\section{Photothermal conversion efficiency and thermal stability}

Nanoprecipitation of NDNT with 1,2-distearoyl-sn-glycero-3phosphoethanolamine- $N$-[amino(polyethylene glycol)-2000] (DSPEPEG $_{\text {-2000}}$ ) was used to improve the water dispersity of NDNT because it is almost insoluble in water. To characterize the morphology of the nanoparticles, dynamic light scattering (DLS) and transmission electronic microscope (TEM) show that the NPs have well-defined spherical nanostructures, and the average diameter distribution is approximately 14 to $90 \mathrm{~nm}$, which is appropriate for enhanced permeability and retention (EPR) in vivo. In order to achieve deep tissue penetration in the near infrared region (NIR) window, NDNT NPs were used in the subsequent experiments.

High photothermal conversion efficiency guarantees high photothermal therapy efficacy. To calculate the photothermal conversion efficiency, the temperature change was recorded. As shown in Fig. 2C, with laser irradiation, the temperature elevation of NDNT NPs is $25.8{ }^{\circ} \mathrm{C}$, which is much higher than that of water under the same condition $\left(4.6{ }^{\circ} \mathrm{C}\right)$. The photothermal conversion efficiency of NDNT NPs was calculated to be as high as $40.6 \%$, promising the excellent phototherapy efficiency of such NPs. The cyclic thermal stability was estimated for 5 times, which is shown in Fig. 2D. It can be found that there is no obvious decay, suggesting the outstanding thermal stability of these NPs.

\section{Cellular uptake, ROS generation and MTT assay in vitro}

The cellular uptake of NDNT NPs in Du145 cells was investigated. As shown in Fig. 3A-D, NDNT NPs can be uptaken by
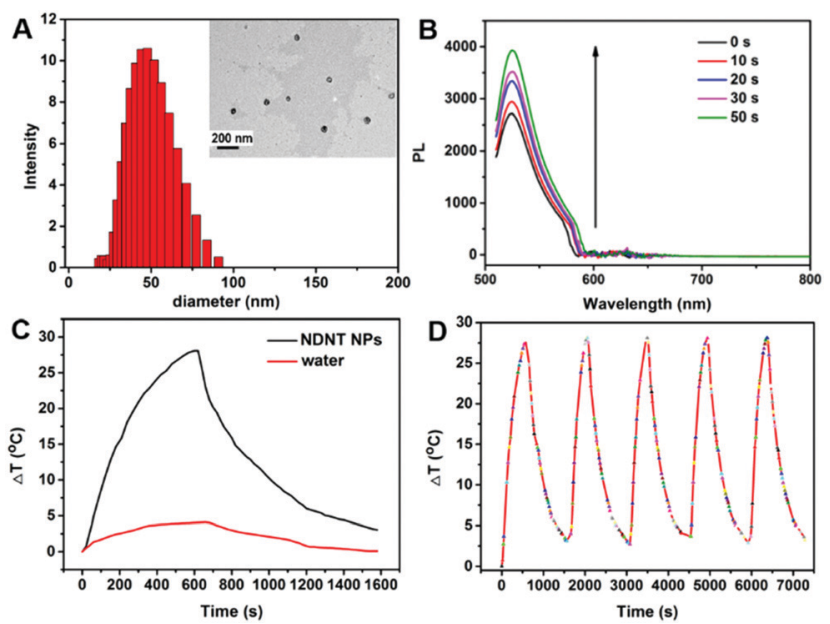

Fig. 2 (A) TEM and DLS of NDNT NPs in water; (B) PL of SOSG with irradiation; (C) heating and cooling curve of NDNT NPs with or without laser irradiation $\left(730 \mathrm{~nm}, 1 \mathrm{~W} \mathrm{\textrm {cm } ^ { - 2 }}\right.$ ); (D) thermal stability of NDNT NPs in water for 5 cycles. 

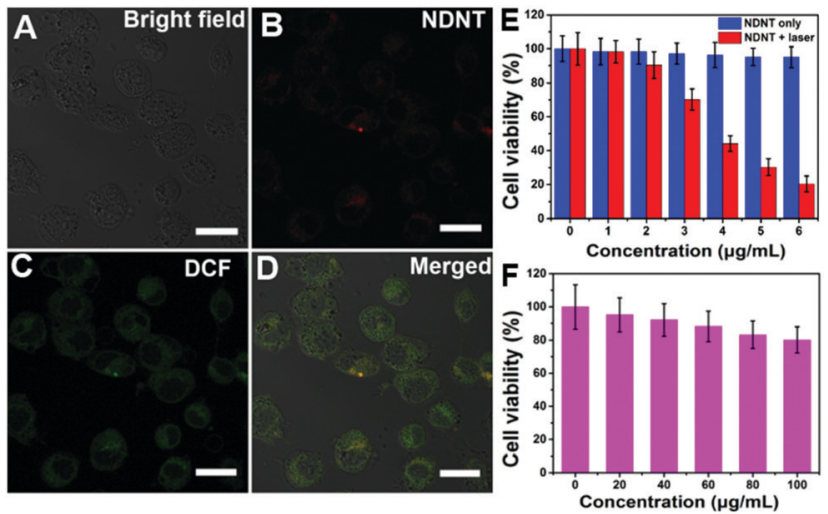

Fig. 3 (A-D) Cellular uptake and ROS generation of NDNT NPs with DCF as a probe in Du145 cells, scale bar: $10 \mu \mathrm{m}$; (E) MTT assay of NDNT NPs with different concentration with or without laser irradiation; (F) cell viability of NDNT NPs at high concentrations without irradiation.

Du145 cells and can generate ROS with DCF as a probe under light irradiation. To investigate the synergistic phototherapeutic effects of the NDNT NPs, we evaluated the inhibitory effect of NDNT NPs on the cell viability of human prostate cells (Du145) at different concentrations. After the treatment of NDNT NPs for $24 \mathrm{~h}$, the MTT assay shows that the $\mathrm{IC}_{50}$ value is as low as $3.8 \mu \mathrm{g} \mathrm{mL}$ (Fig. 3E). In addition, the group incubated with the nanoparticles without irradiation demonstrated a low dark toxicity. To further investigate the potential dark toxicity of the NPs, NDNT NPs were incubated with Du145 at high concentration (Fig. 3F). As a result, the cell viability remains high, showing the suitability of the NPs for PDT/PTT synergistic therapy.

\section{In vivo photothermal imaging guided phototherapy}

To further investigate the PDT and PTT synergistic therapeutic efficacy of NDNT NPs in vivo, 15 nude mice bearing the Du145

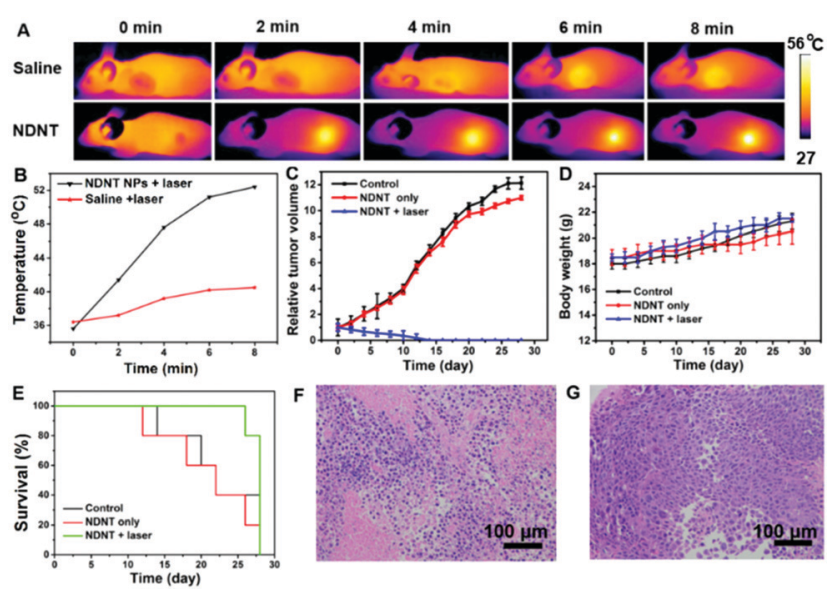

Fig. 4 (A) Photothermal imaging of control and NDNT groups with laser irradiation; (B) temperature elevation of control and NDNT group with irradiation for 2, 4, 6 and $8 \mathrm{~min}$; (C) relative tumor volume of nude mice during treatment; (D) body weight of nude mice; $(E)$ survival rate of nude mice during treatment; $(F)$ H\&E stained picture of the tumor of the control group; (G) H\&E stained picture of the tumors in the NDNT only group. Scale bar: $100 \mu \mathrm{m}$.

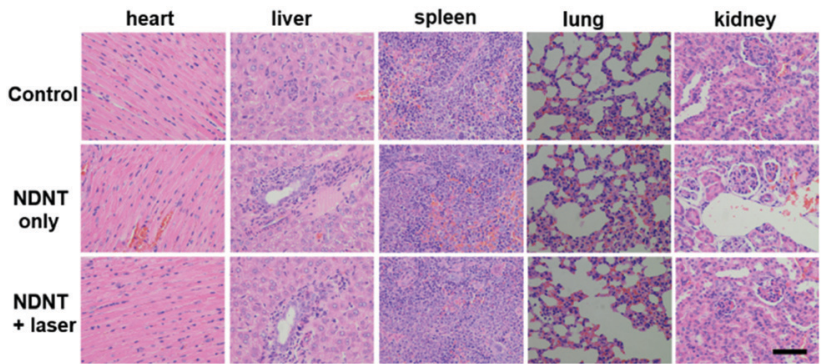

Fig. 5 H\&E stained pictures of normal tissues including the heart, liver, spleen, lung and kidney. Scale bar: $100 \mu \mathrm{m}$.

tumor were used in this study. As shown in Fig. 4A, under the irradiation for $8 \mathrm{~min}$, a significant temperature elevation of approximately $18{ }^{\circ} \mathrm{C}$ was observed, compared with that of the control group $\left(4.2^{\circ} \mathrm{C}\right)$ (Fig. 4B). Fig. $4 \mathrm{C}$ shows that the tumor volume of both the control and the dark group increases at a high speed, while after the irradiation treatment, the tumor volume was greatly suppressed. The tumor of the illumination group completely disappeared even after six treatments, demonstrating the outstanding efficacy of the NDNT NPs. The mice were still alive for 16 days, no obvious recurrence was observed, indicates that NDNT NPs had high phototoxicity for the tumor treatment. Though the NDNT NPs inhibited the growth of tumor in vivo, their potential toxicity must still be comprehensively evaluated. During the treatment process, no significant difference between the body weight of mice in the three groups was observed (Fig. 4D), indicating the low dark toxicity of the NDNT NPs. The survival rate is shown in Fig. $4 \mathrm{E}$.

After treatment, all the mice were sacrificed and the tumors were collected as well as the normal organs, including the heart, liver, spleen, lung, and kidney. According to the hematoxylin and eosin (H\&E) stained images, we found no obvious changes in the normal organs between the control and the NDNT NPs treated groups (Fig. 4F and G). The results indicate that the NDNT NPs exerted anti-tumor activity without any adverse effects in vivo, suggesting their excellent bio-compatibility (Fig. 5). ${ }^{31-36}$

\section{Conclusions}

In summary, a heavy atom-free NDNT with a high ${ }^{1} \mathrm{O}_{2}$ QY of $55.2 \%$ was designed and prepared. The as-prepared NPs obtained by nanoprecipitation with DSPE-PEG -2000 $_{\text {still retained a }}$ high ${ }^{1} \mathrm{O}_{2}$ generation ability with SOSG as a probe, simultaneously providing a high photothermal conversion efficiency (40.6\%), demonstrating the excellent phototherapy efficacy of such NPs. An in vitro MTT assay demonstrates that NDNT NPs with an ultralow $\mathrm{IC}_{50}$ of $3.8 \mu \mathrm{g} \mathrm{mL} \mathrm{m}^{-1}$ show a reasonably low dark toxicity even at a high concentration. In vivo photothermal imaging guided phototherapy indicates that such NPs are able to inhibit the tumor growth in low doses while causing no damage to any normal tissue, suggesting the outstanding biosafety of such NPs. Our research therefore demonstrates the synthesis of a NIR heavy atom-free copolymer with high phototoxicity, low dark toxicity and good biocompatibility for imaging guided synergistic therapy. 


\section{Conflicts of interest}

The authors declare no conflicts of interest.

\section{Acknowledgements}

The authors acknowledge financial support the Fund of the Changshu Health Bureau (No. csws201213).

\section{Notes and references}

1 R. L. Siegel, K. D. Miller and A. J. Dvm, Ca-Cancer J. Clin., 2018, 68, 7-30.

2 K. Ando, M. F. Heymann, V. Stresing, K. Mori, F. Redini and D. Heymann, Cancer, 2013, 5, 591-616.

3 A. Matsunobu, R. Imai, T. Kamada, T. Imaizumi, H. Tsuji, H. Tsujii, Y. Shioyama, H. Honda, S. Tatezaki and W. G. B. S. T. Sarco, Cancer, 2012, 118, 4555-4563.

4 D. Carrle and S. S. Bielack, Int. Orthop., 2006, 30, 445-451.

5 E. E. E. Santala, A. Rannikko and T. J. Murtola, Int. J. Cancer, 2019, 144, 440-447.

6 A. Soldatov, C. A. J. von Klot, D. Walacides, T. Derlin, F. M. Bengel, T. L. Ross, H. J. Wester, K. Derlin, M. A. Kuczyk, H. Christiansen and C. Henkenberens, Int. J. Radiat. Oncol., Biol., Phys., 2019, 103, 1-5.

7 N. Shivran, M. Tyagi, S. Mula, P. Gupta, B. Saha, B. S. Patro and S. Chattopadhyay, Eur. J. Med. Chem., 2016, 122, 352-365.

8 M. Laine, N. A. Barbosa, A. Kochel, B. Osiecka, G. Szewczyk, T. Sarna, P. Ziółkowski, R. Wieczorek and A. Filarowski, Sens. Actuators, B, 2017, 238, 548-555.

9 W. P. Fan, P. Huang and X. Y. Chen, Chem. Soc. Rev., 2016, 45, 6488-6519.

10 Z. J. Zhou, J. B. Song, L. M. Nie and X. Y. Chen, Chem. Soc. Rev., 2016, 45, 6597-6626.

11 A. Carija, N. Puizina-Ivic, D. Vukovic, L. Miric Kovacevic and V. Capkun, Photodiagn. Photodyn. Ther., 2016, 16, 60-65.

12 J. Yang, X. Q. Gu, W. T. Su, X. Y. Hao, Y. J. Shi, L. Y. Zhao, D. F. Zou, G. W. Yang, Q. Y. Li and J. H. Zou, Mater. Chem. Front., 2018, 2, 1842-1846.

13 L. Huang, Z. J. Li, Y. Zhao, J. Y. Yang, Y. C. Yang, A. I. Pendharkar, Y. W. Zhang, S. Kelmar, L. Y. Chen, W. T. Wu, J. Z. Zhao and G. Han, Adv. Mater., 2017, 29, 1604789.

14 G. W. Yang, X. Zhang, G. M. Li, J. Yang, L. Shen, D. Y. Chen, Q. Y. Li and D. F. Zou, New J. Chem., 2018, 42, 5395-5402.

15 Z. Yang, W. P. Fan, W. Tang, Z. Y. Shen, Y. L. Dai, J. B. Song, Z. T. Wang, Y. Liu, L. S. Lin, L. L. Shan, Y. J. Liu, O. Jacobson, P. F. Rong, W. Wang and X. Y. Chen, Angew. Chem., Int. Ed., 2018, 57, 14101-14105.

16 Z. F. Chang, L. M. Jing, B. Chen, M. S. Zhang, X. L. Cai, J. J. Liu, Y. C. Ye, X. D. Lou, Z. J. Zhao, B. Liu, J. L. Wang and B. Z. Tang, Chem. Sci., 2016, 7, 4527-4536.

17 H. He, S. S. Ji, Y. He, A. J. Zhu, Y. L. Zou, Y. B. Deng, H. T. Ke, H. Yang, Y. L. Zhao, Z. Q. Guo and H. B. Chen, Adv. Mater., 2017, 29, 1606690.
18 M. Li, Y. Gao, Y. Y. Yuan, Y. Z. Wu, Z. F. Song, B. Z. Tang, B. Liu and Q. C. Zheng, ACS Nano, 2017, 11, 3922-3932.

19 X. L. Cai, C. J. Zhang, F. T. W. Lim, S. J. Chan, A. Bandla, C. K. Chuan, F. Hu, S. D. Xu, N. V. Thakor, L. D. Liao and B. Liu, Small, 2016, 12, 6576-6585.

20 Y. J. Liu, P. Bhattarai, Z. F. Dai and X. Y. Chen, Chem. Soc. Rev., 2019, 48, 2053-2108.

21 X. S. Li, D. Y. Lee, J. D. Huang and J. Yoon, Angew. Chem., Int. Ed., 2018, 57, 9885-9890.

22 V. Glembockyte, M. Frenette, C. Mottillo, A. M. Durantini, J. Gostick, V. Štrukil, T. Friščić and G. Cosa, J. Am. Chem. Soc., 2018, 140, 16882-16887.

23 W. Sun, S. Y. Li, B. Häupler, J. Liu, S. B. Jin, W. Steffen, U. S. Schubert, H. J. Butt, X. J. Liang and S. Wu, Adv. Mater., 2017, 29, 1603702.

24 Z. W. Wei, M. Wu, S. Y. Lan, J. Li, X. L. Zhang, D. Zhang, X. L. Liu and J. F. Liu, Chem. Commun., 2018, 54, 13599-13602.

25 W. Zheng, G. Yang, S. T. Jiang, N. N. Shao, G. Q. Yin, L. Xu, X. P. Li, G. S. Chen and H. B. Yang, Mater. Chem. Front., 2017, 1, 1823-1828.

26 W. Sun, M. Parowatkin, W. Steffen, H. J. Butt, V. Mailänder and S. Wu, Adv. Healthcare Mater., 2016, 5, 467-473.

27 M. Yamaguchi, S. Ito, A. Hirose, K. Tanaka and Y. Chujo, Mater. Chem. Front., 2017, 1, 1573-1579.

28 B. Wei, M. Y. Guo, Y. M. Lu, P. P. Sun, G. W. Yang and Q. Y. Li, Z. Anorg. Allg. Chem., 2018, 644, 6-11.

29 Z. Y. Fan, D. D. Li, X. Yu, Y. P. Zhang, Y. Cai, J. J. Jin and J. H. Yu, Chem. - Eur. J., 2016, 22, 3681-3685.

30 E. Secret, M. Maynadier, A. Gallud, A. Chaix, E. Bouffard, M. Gary-Bobo, N. Marcotte, O. Mongin, K. El Cheikh, V. Hugues, M. Auffan, C. Frochot, A. Morere, P. Maillard, M. Blanchard-Desce, M. J. Sailor, M. Garcia, J. O. Durand and F. Cunin, Adv. Mater., 2014, 26, 7643-7648.

31 G. Song, J. Hao, C. Liang, T. Liu, M. Gao, L. Cheng, J. Hu and Z. Liu, Angew. Chem., Int. Ed., 2016, 55, 2122-2126.

32 C. R. Gordijo, A. Z. Abbasi, M. Ali Amini, H. Y. Lip, A. Maeda, P. Cai, P. J. O'Brien, R. S. DaCosta, A. M. Rauth and X. Y. Wu, Adv. Funct. Mater., 2015, 25, 1858-1872.

33 Z. Yang, R. Tian, J. Wu, Q. L. Fan, B. C. Yung, G. Niu, O. Jacobson, Z. T. Wang, G. Liu, G. Yu, W. Huang, J. B. Song and X. Y. Chen, ACS Nano, 2017, 11, 4247-4255.

34 Z. Yang, Y. L. Dai, C. Yin, Q. L. Fan, W. Zhang, J. B. Song, G. C. Yu, W. Tang, W. P. Fan, B. C. Yung, J. Li, X. Li, X. Li, Y. Tang, W. Huang, J. B. Song and X. Y. Chen, Adv. Mater., 2018, 30, 1707509.

35 Z. Yang, J. B. Song, W. Tang, W. P. Fan, Y. L. Dai, Z. Y. Shen, L. S. Lin, S. Cheng, Y. Liu, G. Niu, P. Rong, W. Wang and X. Y. Chen, Theranostics, 2019, 9, 526.

36 Z. Yang, Y. L. Dai, L. Shan, Z. Y. Shen, Z. T. Wang, B. C. Yung, O. Jacobson, Y. Liu, W. Tang, S. Wang, L. S. Lin, G. Niu, P. Huang and X. Y. Chen, Nanoscale Horiz., 2019, 4, 426-433. 